\title{
Analysis of spatio-temporal features of a carbon source/sink and its relationship to climatic factors in the Inner Mongolia grassland ecosystem
}

\author{
DAI Erfu', HUANG Yu², "WU Zhuo ${ }^{1,3}$, ZHAO Dongsheng ${ }^{1}$ \\ 1. Key Laboratory of Land Surface Pattern and Simulation, Institute of Geographic Sciences and Natural \\ Resources Research, CAS, Beijing 100101, China; \\ 2. School of Planning, Faculty of Environment, University of Waterloo, Waterloo, ON N2L 3G1, Canada; \\ 3. University of Chinese Academy of Sciences, Beijing 100049, China
}

\begin{abstract}
Global climate change has become a major concern worldwide. The spatio-temporal characteristics of net ecosystem productivity (NEP), which represents carbon sequestration capacity and directly describes the qualitative and quantitative characteristics of carbon sources/sinks (C sources/sinks), are crucial for increasing C sinks and reducing $C$ sources. In this study, field sampling data, remote sensing data, and ground meteorological observation data were used to estimate the net primary productivity (NPP) in the Inner Mongolia grassland ecosystem (IMGE) from 2001 to 2012 using a light use efficiency model. The spatio-temporal distribution of the NEP in the IMGE was then determined by estimating the NPP and soil respiration from 2001 to 2012 . This research also investigated the response of the NPP and NEP to the main climatic variables at the spatial and temporal scales from 2001 to 2012 . The results showed that most of the grassland area in Inner Mongolia has functioned as a $\mathrm{C}$ sink since 2001 and that the annual carbon sequestration rate amounts to $0.046 \mathrm{Pg} \mathrm{C} / \mathrm{a}$. The total net $\mathrm{C}$ sink of the IMGE over the 12-year research period reached $0.557 \mathrm{Pg} \mathrm{C}$. The carbon sink area accounted for $60.28 \%$ of the total grassland area and the sequestered $0.692 \mathrm{Pg} \mathrm{C}$, whereas the $C$ source area accounted for $39.72 \%$ of the total grassland area and released $0.135 \mathrm{Pg} \mathrm{C}$. The NPP and NEP of the IMGE were more significantly correlated with precipitation than with temperature, showing great potential for $\mathrm{C}$ sequestration.
\end{abstract}

Keywords: Inner Mongolia; grassland ecosystem; NPP; NEP; carbon source; carbon sink

\section{Introduction}

Climate change has become a major cause for concern worldwide. Several international

Received: 2015-09-20 Accepted: 2015-10-23

Foundation: National Basic Research Program of China (973 Program), No.2015CB452702, No.2012CB416906; National Natural Science Foundation of China, No.41571098, No.41371196; National Key Technology R\&D Program, No.2013BAC03B04

Author: Dai Erfu (1972-), PhD and Professor, specialized in comprehensive study of physical geography, climate change and regional response, simulation of LUCC. E-mail: daief@igsnrr.ac.cn

"Corresponding author: Wu Zhuo (1988-), PhD Candidate, specialized in land use and ecological process.

E-mail: wuz.14b@igsnrr.ac.cn 
climate negotiations have been held since the establishment of the Intergovernmental Panel on Climate Change in 1988 (Mansanet-Bataller and Pardo, 2008; Houghton et al., 1992). The carbon cycle and the greenhouse effect have long been the focus of global change research programs, such as the Global Carbon Project and the Global Change and Terrestrial Ecosystem (Suand Zhou, 2002). According to the United Nations Framework Convention on Climate Change, the sink or source of greenhouse gases (GHG) refers to any process, activity, or mechanism that eliminates or emits GHG, aerosols, and their precursor compounds from or into the atmosphere (Houghton et al., 2001). Study of the carbon sinks of terrestrial ecosystems has become a point of particular interest in the world because of the challenge of global climate change (Zhan et al., 2012). In recent years, many studies in different regions have addressed carbon sinks using various models and have consistently shown carbon sinks in the Northern Hemisphere at mid-latitude (Battle et al., 2000; Pan et al., 2011; Sarmiento et al., 2010). As gigantic carbon pools, grassland ecosystems are integral for carbon cycling in terrestrial ecosystems (Yang et al., 2010; Yang et al., 2008).

Grasslands of China account for $10 \%$ of the world's total grassland area, and estimations show that they store $9 \%-16 \%$ of the world's total grassland carbon $(\mathrm{Ni}, 2002)$. As one of the dominant types of terrestrial ecosystems, grassland ecosystems serve a variety of ecological purposes, such as functioning as a windbreak and in sand fixation, in water and soil conservation, and in biodiversity protection (Zhao et al., 2004; Adams et al., 1990; Scurlock and Hall, 1998). Grasslands in northern China account for $78 \%$ of the total grassland area in China, and Inner Mongolia grasslands located in the arid and semi-arid climate zones are an important constituent of the Eurasian temperate steppes, and a classic representation of the northern grasslands (Sun, 2005). In addition, they are located in one of the International Geosphere-Biosphere Programme (IGBP) terrestrial transects, which is a region that is very sensitive to climate change (Bai et al., 2008; Steffen et al., 1992). Therefore, it is of great importance to study the carbon sources/sinks (C sources/sinks) and their relationship with climatic factors in the Inner Mongolia grassland ecosystems (IMGE) in order to understand the effects of global climate change. Net primary productivity (NPP) and net ecosystem productivity (NEP) are the two most important indices for quantitatively analyzing $\mathrm{C}$ sources/sinks and can be used to indicate the response of grassland ecosystems to climate change (Woodwell et al., 1978; Raich and Schlesinger, 1992). NEP is an important index used to represent the carbon budget on a larger spatial scale and also to represent the process of carbon exchange between the ecosystem and the atmospheric system (Sitch et al., 2003; Mack et al., 2004; Zhang et al., 2014). The ecosystem is a C sink when the NEP is above zero; otherwise, it is a C source (Woodwell et al., 1978). The variable pattern of the NPP and NEP for grassland ecosystems, which is affected by global climate change, is related to the effect of temperature and precipitation on the metabolism of plants and is also related to the spatial pattern of climatic factors, especially in arid and semi-arid ecosystems (Bai et al., 2004; Zhang et al., 2014). Therefore, accurate assessment of the grassland ecosystem carbon reservoirs in this region and their dynamics will certainly contribute to a better understanding of the relationship between the climate and grassland ecosystems, as well as achieving the sustainable utilization of grassland resources (Niu, 2001; Zhang et al., 2013).

In this study, which was based on field sampling data, remote sensing data and ground meteorological observation data, NPP remote sensing estimation and soil heterotrophic respiration models were used to estimate the NPP and NEP of the IMGE from 2001 to 2012. 
The dynamics of the spatio-temporal features of the NPP and NEP over the same period of time and their relationships with temperature and precipitation were determined, and the spatial distribution of $\mathrm{C}$ sinks and $\mathrm{C}$ sources in the area over the last 10 years was mapped. The results of this study may help to facilitate the adoption and implementation of effective measures to increase $\mathrm{C}$ sinks and decrease $\mathrm{C}$ sources in grassland ecosystems.

\section{Data sources and method}

\subsection{Study area}

The study area covers the temperate steppe in Inner Mongolia, extending from the Greater Hinggan Mountains in the east to Juyan Lake in the west and adjoining Mongolia in the north. The area features a long, narrow strip of sloping land that stretches from northeast to southwest. In 2010, the grasslands in this region, which span approximately $52.15 \times 10^{4} \mathrm{~km}^{2}$, accounted for $44.08 \%$ of the total area of Inner Mongolia. Topographically, the area belongs to the Inner Mongolian Plateau, with an elevation of 1000-1200 m. The landscape is mostly flat. The Greater Hinggan Mountain is in the northeast, and the Yinshan and Helan Mountains are in the southwest. The climate types of the area are semi-humid, semi-arid, and arid, and the hydrothermal conditions in this region are zonally distributed from northeast to southwest. Here, precipitation decreases from $400 \mathrm{~mm}$ to $100 \mathrm{~mm}$, the accumulative temperature $\left(\geq 10^{\circ} \mathrm{C}\right)$ increases from $2050^{\circ} \mathrm{C}$ to $2400^{\circ} \mathrm{C}$, and the Ivanov moisture index decreases from 1.0 to 0.3 (Niu, 2001). In the study area, differences in hydrothermal conditions, topography and other factors result in vegetation spatial heterogeneity, such as meadow steppe (zones IIB3 and IIB1), typical steppe (zones IIC1, IIC2, IIC3, IIC4, and IID1), and desert steppe (zone IID2), in sequence from east to west (Table 1 and Figure 1).

\subsection{Data sources and processing}

To estimate grassland NPP and NEP, and to investigate their relationship with climatic variables, remote sensing images, meteorological data, field sampling data and other results from other mapping techniques were collected and sorted. The remote sensing images were EOS/MODIS vegetation index products MOD13Q1 provided by NASA (https://ladsweb. nascom.nasa.gov/data/search.html), with a temporal resolution of $16 \mathrm{~d}$ and a spatial resolution of $250 \mathrm{~m} \times 250 \mathrm{~m}$. Meteorological data, including temperature and precipitation data, were obtained from the Chinese Surface Monthly Climate Datasets available on the China Meteorological Data Sharing Service System (http://cdc.nmic.cn/home.do). Solar radiation data were derived from the Chinese Monthly Solar Radiation Datasets. Field sampling data were obtained by field sampling from July to August in 2011 and 2012. A total of 120 trial plots were established, and three quadrats of $1 \mathrm{~m} \times 1 \mathrm{~m}$ were distributed randomly in each plot. Aerial biomass samples were collected after removal of the adhered soil and gravel, dried at $65^{\circ} \mathrm{C}$ for $24 \mathrm{~h}$, and then weighed. Other mapping techniques included the land use data and digital elevation model provided by the Resource and Environment Scientific Data Center, Chinese Academy of Sciences.

Data preprocessing mainly involved the processing of remote sensing images and meteorological data. After applying transformation of projection, montage, clip, maximum value composite, and Savitzky-Golay filter to the remote sensing images, monthly MODIS NVDI 
Table 1 Eco-geographical zonal systems of Inner Mongolia

\begin{tabular}{|c|c|c|c|c|}
\hline $\begin{array}{l}\text { Temperature } \\
\text { zones }\end{array}$ & $\begin{array}{l}\text { Humid and arid } \\
\text { zones }\end{array}$ & Codes & Eco-zones & Vegetation type \\
\hline $\begin{array}{l}\text { I Cold tem- } \\
\text { perate zone }\end{array}$ & A (humid zone) & IA 1 & $\begin{array}{l}\text { Deciduous coniferous forest } \\
\text { north of Greater Hinggan Mts. }\end{array}$ & Coniferous forest, wetlanc \\
\hline \multirow[t]{10}{*}{$\begin{array}{l}\text { II Temperate } \\
\text { zone }\end{array}$} & A (humid zone) & IIA3 & $\begin{array}{l}\text { Mixed forest east of Songliao } \\
\text { Plain }\end{array}$ & Mixed forest, wetland \\
\hline & B (semi-humid zone) & IIB1 & $\begin{array}{l}\text { Forest steppe at center of } \\
\text { Songliao Plain }\end{array}$ & Meadow steppe, farmland \\
\hline & & IIB2 & $\begin{array}{l}\text { Steppe forest at the center of } \\
\text { Greater Hinggan Mts. }\end{array}$ & Broadleaf forest, meadow \\
\hline & & IIB3 & $\begin{array}{l}\text { Forest steppe west of Greater } \\
\text { Hinggan Mts. }\end{array}$ & Meadow steppe \\
\hline & $\mathrm{C}$ (semi-arid zone) & IIC1 & Steppe zone in Xiliao River Plain & Typical steppe, farmland \\
\hline & & IIC2 & $\begin{array}{l}\text { Forest steppe south of Greater } \\
\text { Hinggan Mts. }\end{array}$ & Typical steppe, shrub \\
\hline & & IIC3 & $\begin{array}{l}\text { Steppe zone east of Inner } \\
\text { Mongolia }\end{array}$ & Typical steppe, farmland \\
\hline & & IIC4 & Steppe zone of Hulun Buir & Typical steppe, meadow \\
\hline & $\mathrm{D}$ (arid zone) & IID1 & $\begin{array}{l}\text { Desert steppe zone in Ordos and } \\
\text { west of Inner Mongolia }\end{array}$ & Typical steppe, desert \\
\hline & & IID2 & $\begin{array}{l}\text { Desert zone in Alax and } \\
\text { Hexi Corridor }\end{array}$ & Desert, desert steppe \\
\hline $\begin{array}{l}\text { III Warm } \\
\text { temperate } \\
\text { zone }\end{array}$ & B (semi-humid zone) & IIIB3 & $\begin{array}{l}\text { Montane deciduous broadleaf } \\
\text { forest in North China }\end{array}$ & Farmland, typical steppe \\
\hline
\end{tabular}

Note: The eco-zones mentioned above are represented by codes (Zhang et al., 2013).

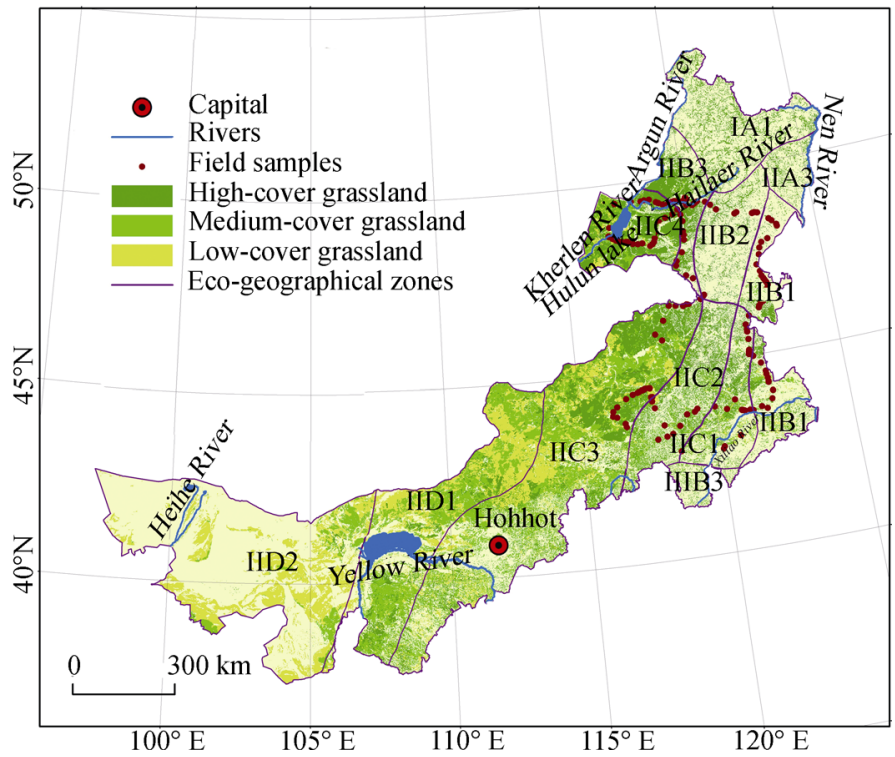

Figure 1 Eco-geographical regionalization, field samples and grassland distribution in Inner Mongolia in 2010

data from 2001 to 2012 in Inner Mongolia were obtained. Temperature and precipitation data were processed using ANUSPLIN, a professional interpolation software for meteorological data based on the theory of the thin plate smoothing spline function and incorporat- 
ing the co-variate linear sub-model, which enhances the precision of spatial interpolation of meteorological data and reflects rates between the meteorological variables and their influencing factors (Liu et al., 2008). Kriging spatial interpolation methods were applied to solar radiation data using the Geostatistical Analyst Module in ArcGIS software.

\subsection{Method}

\subsubsection{Methods for NPP estimation}

NPP, defined as the rate at which all of the plants in an ecosystem accumulate chemical energy through photosynthesis, is calculated by subtracting the value of the gross primary production (GPP) from autotrophic respiration (Ra). NPP estimation has been done by many previous studies around the world (Prince and Goward, 1995; DelGrosso et al., 2008; Goetz et al., 1999; Fang et al., 2000). In this study, the light use efficiency (LUE)-based remote sensing estimation model improved by Zhu et al. (2005) was used to estimate the NPP (g $\mathrm{C} / \mathrm{m}^{2}$ ) in the study area from 2001 to 2012. Compared with other models, there are three advantages to this model. Firstly, it incorporates the classification of vegetation coverage and considers the effects of classification accuracy on NPP estimation. Secondly, combined with observed NPP, the maximum LUE for typical vegetation types in China are simulated based on minimum error, and thus the model is highly suited to China. Finally, this model is combined with existing regional evapotranspiration models, and computation of the water restriction factor is driven by ground meteorological data (Zhu et al., 2007). In this model, NPP can be calculated using the absorbed photosynthetically available radiation (APAR) and real $\operatorname{LUE}(\varepsilon)$ (Eqn. 1). The input parameters include monthly mean temperature, monthly total precipitation, monthly total solar radiation, normalised difference vegetation index (NDVI) time-series data, vegetation map, and static parameter documents. The outputs of this model include time-series documents of NPP and vegetation coverage:

$$
N P P(x, t)=A P A R(x, t) \times \varepsilon(x, t)
$$

where $\operatorname{APAR}(x, t)$ is the solar radiation absorbed by pixel $x$ in the month $t\left(\mathrm{~g} \mathrm{C} / \mathrm{m}^{2}\right)$ and $\varepsilon(x, t)$ is the real LUE of pixel $x$ in the month $t$ (g C/MJ).

\subsubsection{Methods for NEP estimation}

The C sink of an ecosystem corresponds to the difference between NPP and heterotrophic respiration $\left(R_{h}\right)$ regardless of other natural and anthropogenic factors (Eqn. 2):

$$
N E P=N P P-R_{h}
$$

To estimate $R_{h}$, the soil respiration estimation model proposed by Bond-Lamberty et al. (2004) was used (Eqn. 3):

$$
\ln \left(R_{h}\right)=0.22+0.87 \times \ln \left(R_{s}\right)
$$

where $R_{h}$ is the annual rate of soil heterotrophic respiration $\left(\mathrm{kg} \mathrm{C} / \mathrm{m}^{2} \cdot \mathrm{a}\right)$ and $R_{s}$ is the annual rate of soil respiration $\left(\mathrm{kg} \mathrm{C} / \mathrm{m}^{2} \cdot \mathrm{a}\right)$. The model was found to be effective $(p<0.05)$ based on over 100 samples.

To estimate $R_{s}$, the soil respiration model proposed by Raich et al. (2002) was used (Eqn. 4):

$$
R_{s}=f \times e^{\left(b \times T_{a}\right)} \times[P /(k+P)]
$$

where $b$ is the temperature sensitivity coefficient $(b=\ln Q 10 / 10), T_{a}$ is the monthly mean 
temperature $\left({ }^{\circ} \mathrm{C}\right), P$ is the monthly precipitation $(\mathrm{cm})$, and both $f$ and $k$ are constants $(f=1.250, k=4.259)$.

\subsubsection{Interannual variations in NPP and NEP}

The interannual variations in NPP and NEP from 2001 to 2012 were determined using Theil-Sen median tendency analysis. There are certain advantages in estimating the tendency for long time-series data. The Theil-Sen is a non-parametric statistical test for a trend detection data sequence, and it is resistant to data error (Yuan et al., 2013) (Eqn. 5):

$$
S_{N P P / N E P}=\operatorname{Median}\left[\frac{(N P P / N E P)_{j}-(N P P / N E P)_{i}}{j-i}\right], \forall j>i
$$

where $(\mathrm{NPP} / \mathrm{NEP})_{i}$ is the value of NPP or NEP in the year $i$ and (NPP/NEP) $)_{j}$ is the value of NPP or NEP in the year $j$. When NPP/NEP $>0$, NPP or NEP shows an increasing trend. Otherwise, NPP or NEP shows a decreasing trend.

\subsubsection{Correlation analysis}

Based upon the pixels in a local region, spatial analysis was performed to identify correlations between the NPP/NEP of a grassland ecosystem and meteorological variables, such as temperature and precipitation. Subsequently, the biased correlation coefficients were calculated (Mu et al., 2013) (Eqn. 6):

$$
R_{x y}=\frac{\sum_{i=1}^{n}\left[\left(x_{i}-\bar{x}\right)\left(y_{i}-\bar{y}\right)\right]}{\sqrt{\sum_{i=1}^{n}\left(x_{i}-\bar{x}\right)^{2} \sum_{i=1}^{n}\left(y_{i}-\bar{y}\right)^{2}}}
$$

where $R_{x y}$ is the correlation coefficient between $x$ and $y, x_{i}$ is NPP in the year $i . y_{i}$ is mean precipitation or mean temperature in the year $i . \bar{x}$ is the average NPP for years. $\bar{y}$ is mean precipitation or mean temperature over years (2001-2012) and $n$ is the number of samples.

\section{Results}

Based on previously described methods, results were mainly discussed from three aspects: the spatio-temporal characteristics of NPP and NEP, the spatio-temporal dynamics of NPP and NEP, and the response of the main climatic variables to NPP and NEP, and were validated by comparing the estimated and the measured values of NPP.

\subsection{Spatio-temporal characteristics of NPP and NEP}

\subsubsection{Spatio-temporal characteristics of NPP}

Generally, the NPP of grasslands in Inner Mongolia decreased from east to west from 2001 to 2012 (Figure 2). The average annual NPP and total annual NPP in this region were 278.83 $\mathrm{g} \mathrm{C} / \mathrm{m}^{2}$ and $0.146 \mathrm{Pg} \mathrm{C}$, respectively. Comparison between NPPs in different eco-geographical zones showed a strong spatial heterogeneity and a longitudinal zonal pattern (Table 2). The highest value of NPP was in the northern forest steppe zone, followed by the typical central and western desert steppe zones. 
The major vegetation type in the east of Inner Mongolia was meadow, which was mingled with forests. Because of the effect of the forests on the transitional region, the grassland productivity was relatively higher than that of any other zones. This type of ecosystem was mainly distributed in zones IIB3 and IIB1, where the average annual NPPs were $487.44 \mathrm{~g} \mathrm{C} / \mathrm{m}^{2}$ and $405.04 \mathrm{~g} \mathrm{C} / \mathrm{m}^{2}$, respectively. In central Inner Mongolia, the major vegetation cover was typical steppe, which comprises the main body of the Inner Mongolia steppe. The average annual NPP in this area ranged from $200 \mathrm{~g} \mathrm{C} / \mathrm{m}^{2}$ to $500 \mathrm{~g}$ $\mathrm{C} / \mathrm{m}^{2}$. In addition, the average annual grassland NPPs in zones IIC2, IIC1, IIC4,

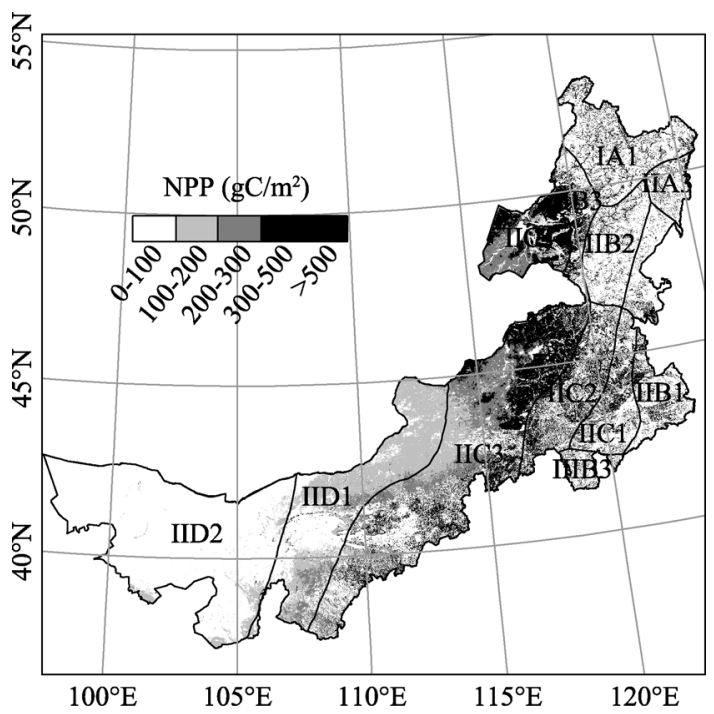

Figure 2 Spatial distribution of average NPP in the Inner Mongolia grassland ecosystem from 2001 to 2012 and IIC3 were 466.14, 363.14, 323.67, and $301.91 \mathrm{~g} \mathrm{C} / \mathrm{m}^{2}$, respectively, and the average annual NPP to the west of zones IIC3 and IIC4 only ranged from $200 \mathrm{~g} \mathrm{C} / \mathrm{m}^{2}$ to $300 \mathrm{~g} \mathrm{C} / \mathrm{m}^{2}$. In the west of Inner Mongolia, the major vegetation cover was desert steppe and typical steppe. The average annual grassland NPP ranged from $0 \mathrm{~g} \mathrm{C} / \mathrm{m}^{2}$ to $200 \mathrm{~g} \mathrm{C} / \mathrm{m}^{2}$. This type of ecosystem was mainly concentrated in zones IID1 and IID2, and the average annual NPP in these areas were $153.08 \mathrm{~g} \mathrm{C} / \mathrm{m}^{2}$ and $76.48 \mathrm{~g} \mathrm{C} / \mathrm{m}^{2}$, respectively.

\subsubsection{Spatio-temporal characteristics of NEP}

Similarly, the accumulated interannual NEP in Inner Mongolia from 2001 to 2012 showed a significant decreasing trend from east to west (Figure 3 ). The areas occupied by the $\mathrm{C}$ sink

Table 2 Average NPP in eco-geographical zones of the Inner Mongolia grassland ecosystem from 2001 to 2012

\begin{tabular}{cc}
\hline Eco-zones & $\mathrm{NPP}\left(\mathrm{g} \mathrm{C} / \mathrm{m}^{2}\right)$ \\
\hline IA1 & 590.99 \\
IIA3 & 591.27 \\
IIB1 & 405.05 \\
IIB2 & 593.64 \\
IIB3 & 487.52 \\
IIC1 & 363.16 \\
IIC2 & 466.15 \\
IIC3 & 301.88 \\
IIC4 & 323.65 \\
IID1 & 153.05 \\
IID2 & 76.45 \\
IIIB3 & 528.94 \\
\hline
\end{tabular}

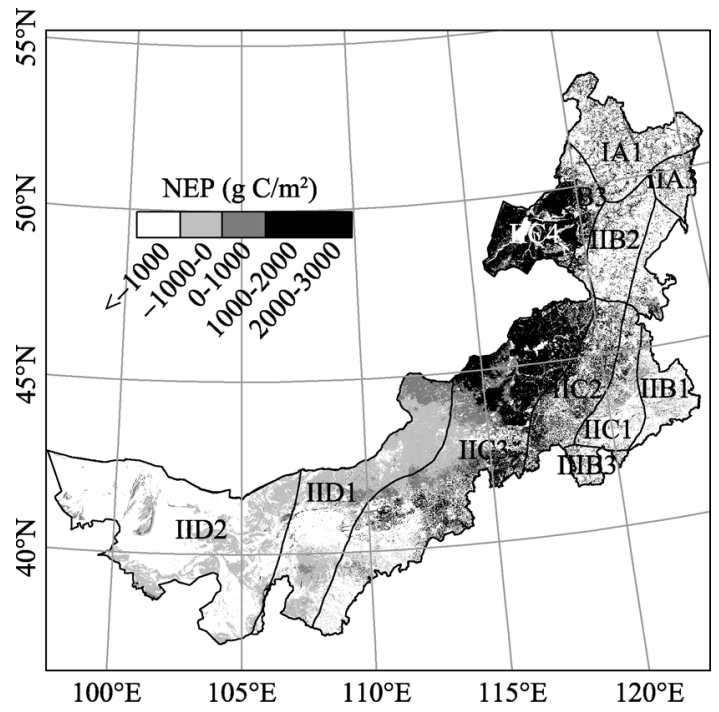

Figure 3 Spatial distribution of the total NEP in the Inner Mongolia grassland ecosystem from 2001 to 2012 
Table 3 Average NEP in eco-geographical zones of the Inner Mongolia grassland ecosystem from 2001 to 2012

\begin{tabular}{cc}
\hline Eco-zones & NEP $\left(\mathrm{g} \mathrm{C} / \mathrm{m}^{2}\right)$ \\
\hline IA1 & 4448.90 \\
IIA3 & 3972.41 \\
IIB1 & 1297.88 \\
IIB2 & 4353.57 \\
IIB3 & 3194.29 \\
IIC1 & 885.54 \\
IIC2 & 2626.31 \\
IIC3 & 715.18 \\
IIC4 & 1295.56 \\
IID1 & -960.22 \\
IID2 & -1436.88 \\
IIIB3 & 2849.03 \\
\hline
\end{tabular}

$(\mathrm{NEP}>0)$ and $\mathrm{C}$ source $(\mathrm{NEP}<0)$ sectors were approximately $31.43 \times 10^{4} \mathrm{~km}^{2}(60.28 \%$ of the total steppe area) and $20.71 \times 10^{4} \mathrm{~km}^{2}(39.72 \%$ of the total steppe area), respectively. The average quantity of $\mathrm{C}$ sequestered by the grassland ecosystem in the $\mathrm{C}$ sink sector over the past 12 years was $2201.25 \mathrm{~g} \mathrm{C} / \mathrm{m}^{2}$, and the total $\mathrm{C}$ sequestration for the entire study area was approximately $0.692 \mathrm{Pg} \mathrm{C}$. The average grassland ecosystem $\mathrm{C}$ emitted in the $\mathrm{C}$ source sector over the past 12 years was $651.47 \mathrm{~g} \mathrm{C} / \mathrm{m}^{2}$, and the total $\mathrm{C}$ emission in the entire study area was approximately $0.135 \mathrm{Pg} \mathrm{C}$. In addition, the total amount of net $\mathrm{C}$ sink in the IMGE was as high as $0.557 \mathrm{Pg} \mathrm{C}$ from 2001 to 2012 , and the annual rate of $\mathrm{C}$ sequestration was $0.046 \mathrm{Pg} \mathrm{C} / \mathrm{a}$.

The $\mathrm{C}$ source/sink distribution of grassland ecosystems in different eco-zones showed spatial distinction and longitudinal zonation (Table 3). The C sink sector was mainly represented by zones IIB3, IIC2, IIC4, and IIC3, where the average accumulated $C$ over the past 12 years was $3967.65,3028.35,2085.38$, and $1146.61 \mathrm{~g} \mathrm{C} / \mathrm{m}^{2}$, respectively. The IIB1 steppe zone in the central area of the Songliao Plain and the IIC1 steppe zone in the Xiliao River Plain were generally C sinks, but their C sink capability was relatively low, with average accumulated $\mathrm{C}$ sequestrations of 607.85 and $428.10 \mathrm{~g} \mathrm{C} / \mathrm{m}^{2}$, respectively, from 2001 to 2012 . The $\mathrm{C}$ source sector mainly covered zones IID1 and IID2, with average annual C emissions of 383.05 and $530.69 \mathrm{~g} \mathrm{C} / \mathrm{m}^{2}$, respectively. Additionally, the south of IIB1 and the southwest of IIC1 were also shown to be $\mathrm{C}$ sources.

\subsection{Spatio-temporal dynamics of NPP and NEP}

\subsubsection{Interannual variations of NPP and NEP}

The NPP and NEP of the IGME increased throughout the study period (Figure 4). The average annual NPP ranged from $200 \mathrm{~g} \mathrm{C} / \mathrm{m}^{2}$ to $350 \mathrm{~g} \mathrm{C} / \mathrm{m}^{2}$ and the NEP ranged from $50 \mathrm{~g}$ $\mathrm{C} / \mathrm{m}^{2}$ to $150 \mathrm{~g} \mathrm{C} / \mathrm{m}^{2}$. The annual growth rates of the NPP and NEP were 3.781 and $2.104 \mathrm{~g}$ $\mathrm{C} / \mathrm{m}^{2} \cdot \mathrm{a}$, respectively. Looking at the time series, the NPP and NEP were hardly synchronized from 2001 to 2012. The oscillations and variations of the NPP and NEP over the past 12 years suggested that the NEP was closely linked to the NPP and to

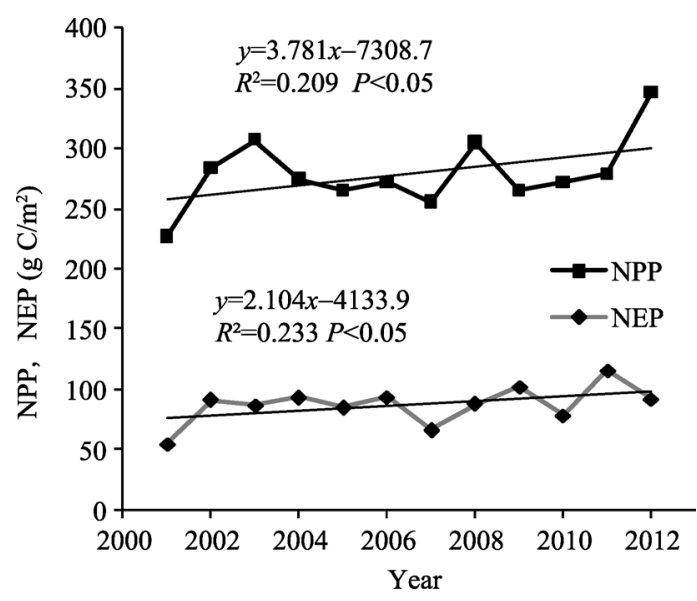

Figure 4 The variation trend in NPP and NEP in the Inner Mongolia grassland ecosystem from 2001 to 2012 
soil respiration.

\subsubsection{Spatio-temporal dynamics of NPP}

The NPP in the grassland ecosystems in most parts of Inner Mongolia showed an increasing trend from 2001 to 2012 (Figure 5).

The average growth rate was $3.56 \mathrm{~g}$ $\mathrm{C} / \mathrm{m}^{2} \cdot 12 \mathrm{a}$. The area of grassland that showed an increased NPP was $43.56 \times 10^{4}$ $\mathrm{km}^{2}$, accounting for $83.6 \%$ of the total steppe area. Areas showing an NPP growth rate from $0-5 \mathrm{~g} \mathrm{C} / \mathrm{m}^{2} \cdot 12 \mathrm{a}$ accounted for $47.3 \%$, those showing an NPP growth rate from 5-10 $\mathrm{g} \mathrm{C} / \mathrm{m}^{2} \cdot 12 \mathrm{a}$ accounted for $26.64 \%$, and those showing an NPP growth rate from $10-15 \mathrm{~g} \mathrm{C} / \mathrm{m}^{2} \cdot 12 \mathrm{a}$ accounted for $8.21 \%$. Consequently, only $1.45 \%$ of the NPP growth rate exceeded $15 \mathrm{~g} \mathrm{C} / \mathrm{m}^{2} \cdot 12 \mathrm{a}$. The area of grassland showing a decreased

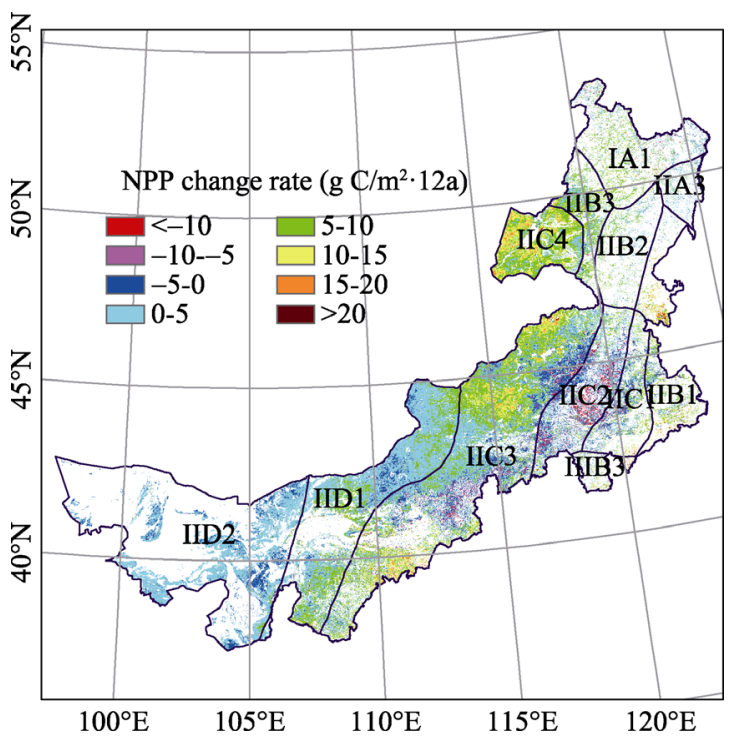

Figure 5 Spatio-temporal pattern and NPP average change rate in the Inner Mongolia grassland ecosystem from 2001 to 2012

NPP was $8.55 \times 10^{4} \mathrm{~km}^{2}$, or $16.4 \%$ of the total steppe area. Grassland showing a negative NPP growth rate from $0-10 \mathrm{~g} \mathrm{C} / \mathrm{m}^{2} \cdot 12 \mathrm{a}$ accounted for $12.76 \%$ of the total steppe area, and only $3.64 \%$ of the negative NPP growth rate exceeded $10 \mathrm{~g} \mathrm{C} / \mathrm{m}^{2} \cdot 12 \mathrm{a}$.

Even if an increase in the grassland NPP was evident, the grassland NPP in most parts of Inner Mongolia showed no distinct spatial distribution features from east to west during 2001-2012 (Table 4). The NPP increase was clustered together in the northeastern study area, including zones IIC4, IIB1, and IIB3, with growth rates of $8.66,7.12$, and $5.72 \mathrm{~g} \mathrm{C} / \mathrm{m}^{2} \cdot 12 \mathrm{a}$, respectively. The NPP significantly decreased area was mainly concentrated in zone IIC2,

Table 4 Trend in NPP in eco-geographical zones of the Inner Mongolia grassland ecosystem from 2001 to 2012

\begin{tabular}{cc}
\hline Eco-zones & $\mathrm{S}_{N P P}$ \\
\hline IA1 & 5.55 \\
IIA3 & 3.17 \\
IIB1 & 7.44 \\
IIB2 & 4.34 \\
IIB3 & 6.36 \\
IIC1 & 3.01 \\
IIC2 & -1.99 \\
IIC3 & 3.07 \\
IIC4 & 11.40 \\
IID1 & 3.04 \\
IID2 & 0.93 \\
IIIB3 & 3.73 \\
\hline
\end{tabular}
with a negative growth rate of $1.45 \mathrm{~g} \mathrm{C} / \mathrm{m}^{2} \cdot 12 \mathrm{a}$.

\subsubsection{Spatio-temporal dynamics of NEP}

The NEP also increased in most parts of the Inner Mongolia steppe from 2001 to 2012 (Figure 6). The average annual growth rate was approximately $2.16 \mathrm{~g} \mathrm{C} / \mathrm{m}^{2} \cdot 12 \mathrm{a}$, which was slightly lower than that of the NPP. Overall, the pattern of variation was consistent with that of the NPP, which suggested that the increase in the grassland NPP may partly denote the increase in grassland carbon sequestration. The area of the increased NEP grassland in the entire region was $36.9 \times 10^{4} \mathrm{~km}^{2}$, accounting for $70.8 \%$ of the total steppe area. Areas showing an NEP growth rate ranging from $0-5 \mathrm{~g} \mathrm{C} / \mathrm{m}^{2} \cdot 12 \mathrm{a}$ accounted for $43.23 \%$ of the total steppe area, those showing an NEP growth rate ranging from 


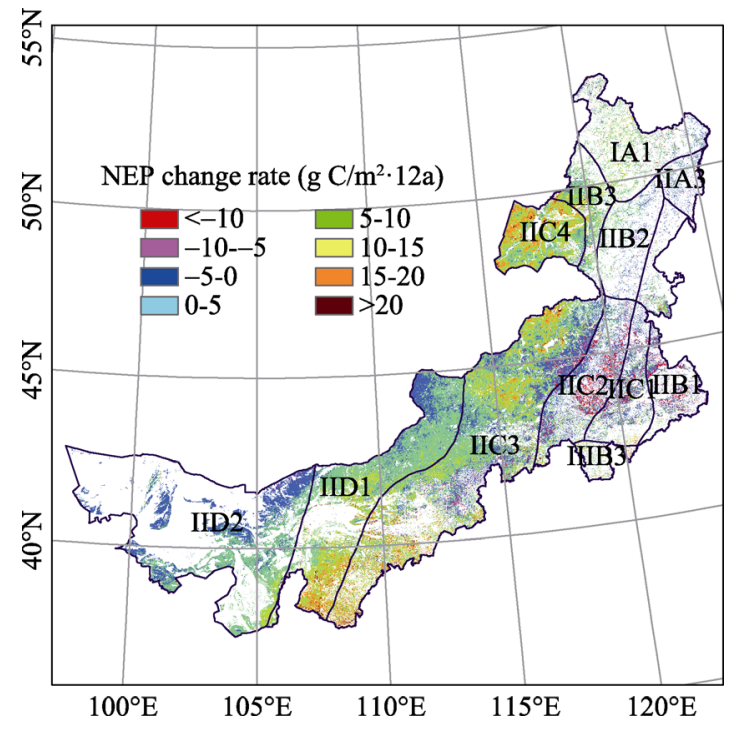

Figure 6 Spatio-temporal pattern and the NEP average change rate in the Inner Mongolia grassland ecosystem from 2001 to 2012
5-10 g C $/ \mathrm{m}^{2} \cdot 12 \mathrm{a}$ accounted for $21.05 \%$ of the total steppe area, and those showing an NEP growth rate from $10-15 \mathrm{~g} \mathrm{C} / \mathrm{m}^{2} \cdot 12 \mathrm{a}$ accounted for $5.69 \%$. Consequently, only $0.83 \%$ of the NEP growth rate exceeded 15 $\mathrm{g} \mathrm{C} / \mathrm{m}^{2} \cdot 12 \mathrm{a}$. The area of the decreased-NEP grassland was $8.55 \times 10^{4} \mathrm{~km}^{2}$, or $29.2 \%$ of the total steppe area, which was larger than that of the decreased-NPP grassland. $27.65 \%$ of this total area showed a negative NEP growth rate ranging from $0-10 \mathrm{~g}$ $\mathrm{C} / \mathrm{m}^{2} \cdot 12 \mathrm{a}$, and only $1.55 \%$ of this area showed a rate above $10 \mathrm{~g} \mathrm{C} / \mathrm{m}^{2} \cdot 12 \mathrm{a}$.

The NEP in most parts of the Inner Mongolia steppe showed an increasing trend during the study period, which was very similar to the NPP trend, but the growth rate varied across different zones

(Table 5). The NEP increased most in the northeastern part of the area studied, including zones IIC4 and IIB3 with average growth rates of $6.62 \mathrm{~g} \mathrm{C} / \mathrm{m}^{2} \cdot 12 \mathrm{a}$ and $3.67 \mathrm{~g} \mathrm{C} / \mathrm{m}^{2} \cdot 12 \mathrm{a}$, respectively. This was followed by the central and western parts, including zones IID1, IIC3, and IID2 with average growth rates of 3.66, 3.25 and $0.44 \mathrm{~g} \mathrm{C} / \mathrm{m}^{2} \cdot 12 \mathrm{a}$, respectively. In zones IIC2, IIB1 and IIC1, the NEP decreased significantly, with average negative growth rates of $3.14,2.84$, and $1.85 \mathrm{~g} \mathrm{C} / \mathrm{m}^{2} \cdot 12 \mathrm{a}$, respectively.

\subsection{Response of main climatic variables to NPP and NEP}

\subsubsection{Patterns of temperature and precipitation}

The spatial distribution of the annual mean temperature (AMT) and annual precipitation (AP) in the study area over the period 20012012 is shown in Figure 7. The AMT was $3.82^{\circ} \mathrm{C}$, and the AP was $263.97 \mathrm{~mm}$. Additionally, climatic variables displayed significant spatial variation, showing an increasing trend in precipitation (Figure 7a) and a decreasing trend in temperature from south-west to north-east (Figure 7b).

The eastern meadow steppe region, represented by zone IIB3, has a cold and temperate continental monsoon climate with cold, dry and long winters and warm, humid, and short summers. This area has an annual temperature ranging from $-3^{\circ} \mathrm{C}$ to $8^{\circ} \mathrm{C}$ and an annual pre-
Table 5 Trend in NEP in eco-geographical zones of the Inner Mongolia grassland ecosystem from 2001 to 2012

\begin{tabular}{cc}
\hline Eco-zones & \multicolumn{1}{c}{$\mathrm{S}_{N E P}$} \\
\hline IA1 & 2.40 \\
IIA3 & -1.75 \\
IIB1 & -2.35 \\
IIB2 & -0.51 \\
IIB3 & 3.11 \\
IIC1 & -3.50 \\
IIC2 & -2.83 \\
IIC3 & 3.55 \\
IIC4 & 7.57 \\
IID1 & 3.35 \\
IID2 & 2.04 \\
IIIB3 & 1.06 \\
\hline
\end{tabular}


cipitation of 350-580 mm. By contrast, zone IIB1, which lies in a transitional area between semi-humid and semi-humid climate zones, has an AMT of $5-7^{\circ} \mathrm{C}$ and an annual precipitation of $300-550 \mathrm{~mm}$. The typical central steppe ecosystem is mainly concentrated in the semi-arid climate zone, including zones IIC1, IIC2, IIC3 and IIC4, and both AP and AMT show a southwest to northeast gradient. This region also experiences a temperate continental monsoon climate, which is dominated by a polar continental air mass with high-latitude inland north winds prevailing in winter and by a polar marine air mass with prevailing eastern and southeastern winds. Fortunately, pastures benefit from the concurrence of hot months and precipitation. From east to west, the AP in the Hulun Buir, Xilin Gol, and Ulan Qab plateaus progressively decreased, whereas the AMT progressively increased. The western desert steppe region is mainly concentrated in the semi-arid climate zone, including zones IID1 and IID2, where the climate type is temperate dry monsoon with an AP below $150 \mathrm{~mm}$ and an AMT of $7^{\circ} \mathrm{C}$ or above. Controlled by a cold air mass, the winter is long and extremely cold without much snowfall, whereas the summer season is dry with little rainfall, which is mainly controlled by westerly and subtropical winds. The disadvantageous hydrothermal combination in this region has a negative effect on the growth of the pasture, resulting in fluctuations in pasture production and quality, leading ultimately to widespread degradation.
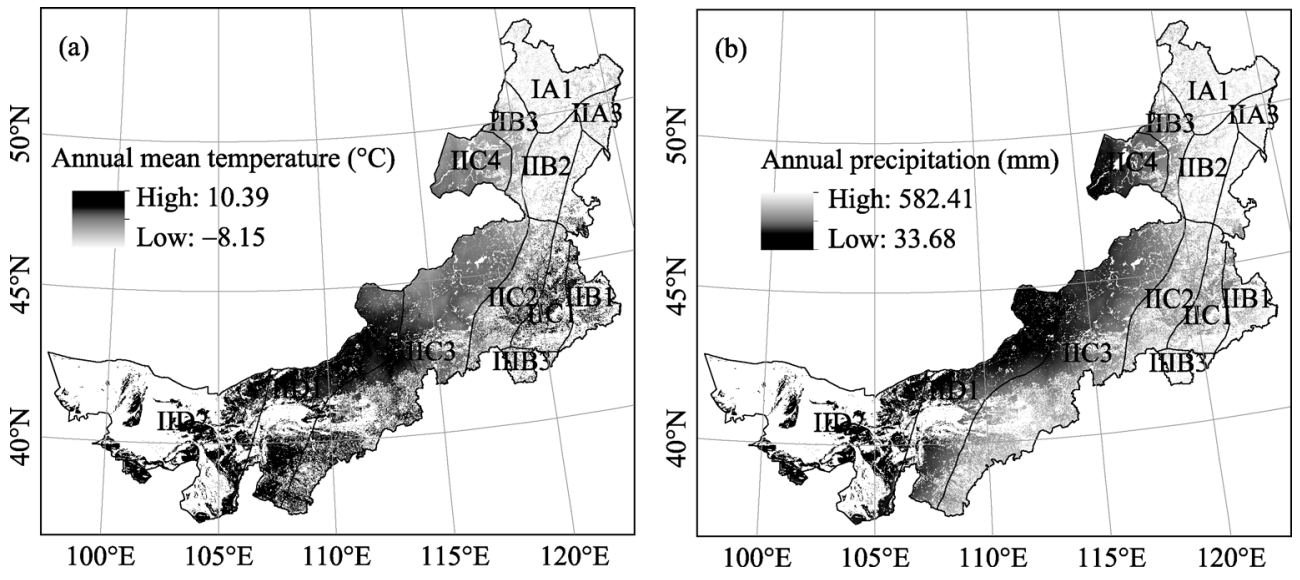

Figure 7 The spatial pattern of the annual mean temperature (a) and the annual precipitation (b) in the Inner Mongolia grassland ecosystem from 2001 to 2012

\subsubsection{Response of temperature and precipitation to NPP}

Overall, NPP and temperature showed a negative correlation (Figure 8a), and the mean correlation coefficient for the entire area was -0.117 . The area of grassland with a positive correlation between NPP and AMT was $18.2 \times 10^{4} \mathrm{~km}^{2}$, which accounted for $34.92 \%$ of the total steppe area. These areas were mainly concentrated in the south of the IIC3 steppe zone, the north of the IID1 desert steppe zone in Ordos, the IIC1 steppe zone in the Xiliao River Plain, and the IIC2 south Greater Hinggan Mountain forest steppe zone. The area of grassland with NPP negatively correlated with AMT was $33.82 \times 10^{4} \mathrm{~km}^{2}$, which accounted for $64.89 \%$ of the total steppe area. These areas were mainly concentrated in the southeast of the IIB3 west Greater Hinggan Mountain forest steppe zone, in the IIC4 Hulun Buir steppe zone, 
the south of the IIC3 steppe zone in eastern Inner Mongolia, and the south of the IID1 desert steppe zone in Ordos. The distribution of correlation significance showed no strong consistency between the NPP and temperature in most parts of the study area, which suggested that temperature was not a climatic restricting factor influencing the grassland NPP in Inner Mongolia.

NPP and precipitation mostly showed a positive correlation (Figure 8b), and the mean correlation coefficient for the entire study area was 0.53 . The area of grassland with NPP that was positively correlated with AP was $49.11 \times 10^{4} \mathrm{~km}^{2}$, which accounted for $94.24 \%$ of the total steppe area, which extended to zones IIC3 and IIC4 in the typical steppe and zones IID1 and IID2 in the desert steppe. The area of grassland with NPP that was positively correlated with AP was $3.01 \times 10^{4} \mathrm{~km}^{2}$, which accounted for $5.76 \%$ of the total steppe area and was mainly concentrated in zone IIB3 where precipitation was a restricting factor in the NPP. The distribution of significance (Figure $8 \mathrm{~b}$ ) showed that NPP and precipitation were most positively correlated in zones IIC3, IIC4, and IID1. This correlation was not negative in other zones, nor was it significant. Therefore, the major climate restricting factor of the NPP in Inner Mongolia was precipitation, and optimal hydrothermal conditions are required for pastures to flourish in this area.
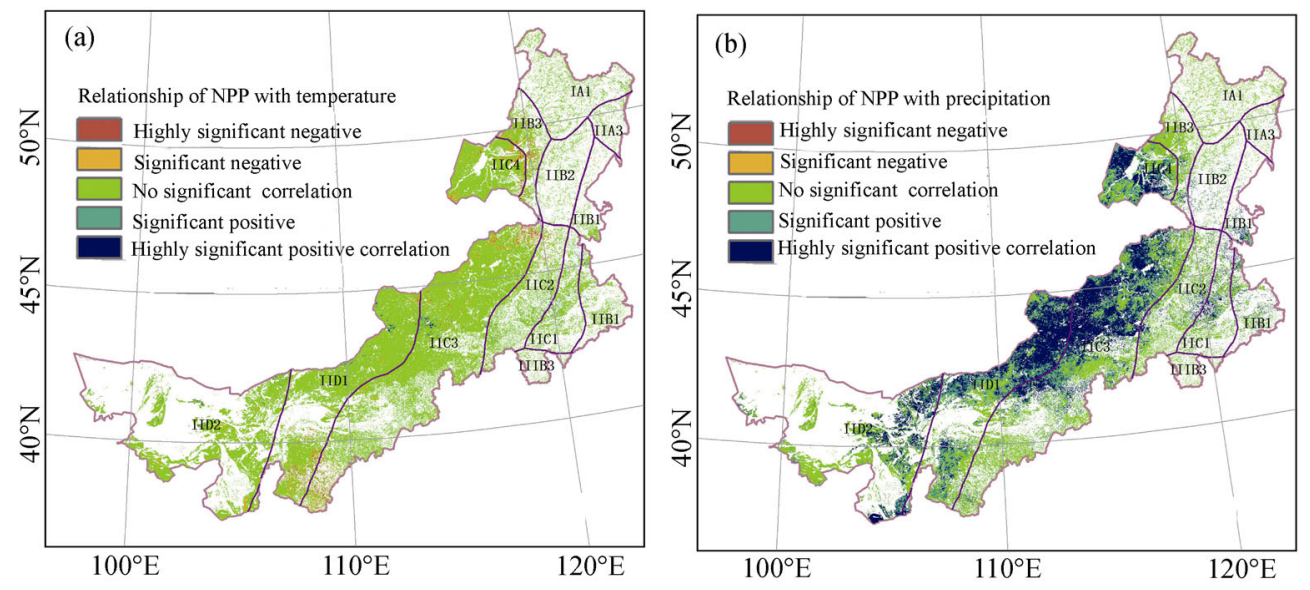

Figure 8 The significant relationship of NPP with temperature (a) and precipitation (b) in the Inner Mongolia grassland ecosystem

\subsubsection{Response of temperature and precipitation to NEP}

NEP and temperature were mostly negatively correlated (Figure 9a), and the mean correlation coefficient for the entire area was -0.132 . The area of grassland with NEP that was positively correlated with the AMT was $17.84 \times 10^{4} \mathrm{~km}^{2}$, which accounted for $34.23 \%$ of the total steppe area. These areas were mainly concentrated in zones IID1 and IID2, where the grassland NEP increased with temperature increase. The area of grassland with NEP that was negatively correlated with the AMT was $34.28 \times 10^{4} \mathrm{~km}^{2}$, which accounted for $65.72 \%$ of the total steppe area. These areas were mainly concentrated in zones IIC4, IIB3, and the north of zone IIC3. The distribution of correlation significance showed no strong correlation between grassland NEP and temperature in most parts of the study area, which suggested that temperature was not a restricting factor for the grassland NEP in Inner Mongolia. 

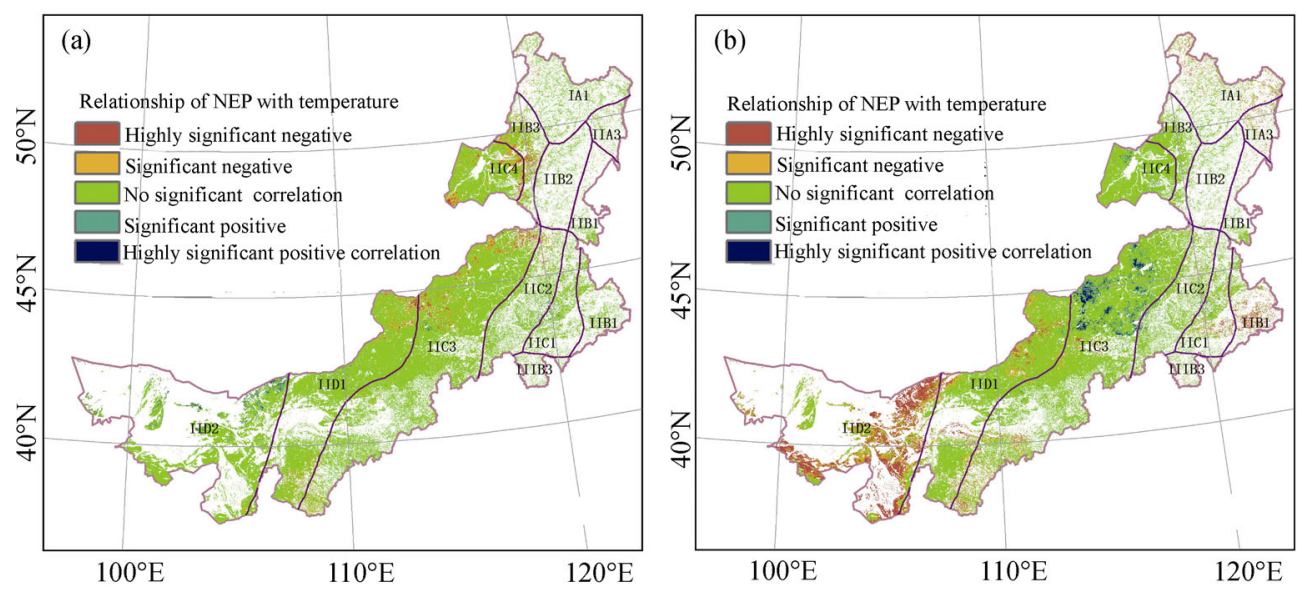

Figure 9 The significant relationship of NEP with temperature (a) and precipitation (b) in the Inner Mongolia grassland ecosystem

The correlation between NEP and precipitation was positive in some sub-areas, whereas it was negative in others (Figure 9b). The mean correlation coefficient for the entire area was 0.15 . The area of grassland with NEP that was positively correlated with AP was $19.38 \times 10^{4}$ $\mathrm{km}^{2}$, which accounted for $37.18 \%$ of the total area. These areas were mainly concentrated in the IIC4 Hulun Buir steppe zone and the IIC3 steppe zone east of Inner Mongolia. The grassland with NEP that was negatively correlated with the AP was mainly concentrated in zones IIB3, IIB1, IID1 and IID2. The distribution of correlation significance showed that grasslands with a positive correlation between NEP and precipitation were mainly concentrated in the IIC3 steppe zone east of Inner Mongolia. However, the grasslands with NEP that were negatively correlated with precipitation were mainly concentrated in zone IID2. No significant correlation was observed between NEP and precipitation in other areas.

\subsection{Validation}

The estimated and measured NPP from 2011 to 2012 showed a positive correlation (Figure 10, $R^{2}=0.54$ ), but the simulated NPP values were relatively scattered and generally higher than the actual measured values. This might be because the NPP includes biomass that accumulated underground. However, for some species no consistent linear relationship exists between underground biomass and above-ground biomass. In general, the average interannual grassland NPP in Inner Mongolia may be estimated to be $278.83 \mathrm{~g}$ $\mathrm{C} / \mathrm{m}^{2}$. Bao et al. (2009) estimated the grassland NPP in Inner Mongolia using MODIS data and the CASA model. They found an average NPP value of $262.05 \mathrm{~g} \mathrm{C} / \mathrm{m}^{2}$ from

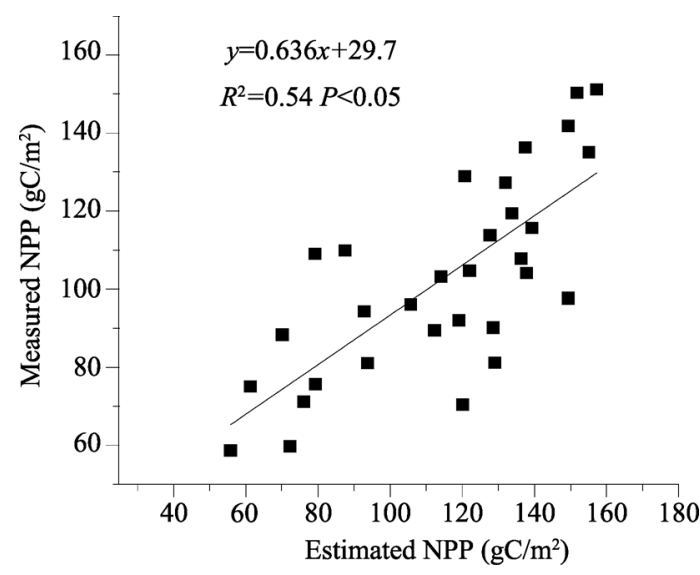

Figure 10 The relationship between the estimated and the measured values of NPP in 2011 and 2012 
2002 to 2006, which is similar to the results reported in this paper. The figures for the estimation and spatial distribution of the NEP in this study were similar to the results of Tao et al. (2006), whose work was based on the CEVSA model. Uncertainties in the estimation of the NPP can be reduced by enhancing data accuracy, parameter adjustment and observation experiments. However, the uncertainty about soil respiration is a much more complex problem. The soil respiration model adopted in this research was constructed using the results for over 1000 samples, using the Bond-Lamberty and Thomson method (Bond-Lamberty et al., 2004), but most of the data for this model were not collected throughout the year and were only extrapolated from soil respiration rates during the growing season. Such errors are not negligible and this model will inevitably influence the accurate estimation of soil respiration, leading to uncertainties in NEP estimation.

\section{Discussion}

Several uncertainties in the NPP and NEP estimation may be observed in this study. Firstly, the resolution of the remote sensing images was $1 \mathrm{~km} \times 1 \mathrm{~km}$. The NPP retrieved using satellite data was taken as the mean value of a $1 \mathrm{~km}^{2}$ area, but measured sampling was carried out in an area of $1 \mathrm{~m}^{2}$. Disparities in spatial resolution may cause estimation errors. Secondly, the pasture is composed of various plant species. Extracting accurate information on the species from mixed image cells of the remote sensing data is impossible, and our measured samples did not cover all of the relevant species in this area. The NEP represents the net photosynthetic productivity of an ecosystem and indicates its $C$ sequestration capability. The ecosystem is a $\mathrm{C}$ source when the NEP $<0$ and is a $\mathrm{C}$ sink when the NEP $>0$. This index has been extensively applied to global C cycling since the 1990s. However, net biome productivity (NBP) was recently proposed as a indicator at a larger scale, which is calculated by subtracting the value of the NEP from the value of the non-biotic respiration (NR) induced by natural and anthropogenic disturbances, such as forest fires, pests, defoliation, forestry cutting and production (Fang et al., 2001). Issues concerning how to distinguish between abiotic and biotic effects and quantitative assessments of $\mathrm{C}$ sequestration capability should be addressed in the future studies. In this paper, only the effects of climatic variables, such as precipitation and temperature, on the spatial distribution of NPP and NEP are discussed. Other factors, such as soil heterotrophic respiration and nitrogen deposition (Peng et al., 2014), have been ignored. In the future, both natural factors (e.g., radiation, evaporation and carbon dioxide concentration) and anthropogenic factors (e.g., grazing and enclosure) must be fully incorporated into the process of $\mathrm{C}$ sequestration in regional ecosystems to clarify the effects of climate change and anthropogenic activities on the capability of $\mathrm{C}$ sinks.

\section{Conclusions}

In this study, the NPP and NEP of the IMGE were estimated from 2001 to 2012 based on NPP remote sensing estimation and soil heterotrophic respiration models. Dynamics in the spatio-temporal features of NPP and NEP during the study period and their relationships with temperature and precipitation were also analyzed. The main results are as follows:

(1) In general, the NPP and NEP in the IMGE showed higher values in the east and lower values in the west from 2001 to 2012, with mean NPPs of $278.83 \mathrm{~g} \mathrm{C} / \mathrm{m}^{2}$. During this period, 
the $\mathrm{C}$ sink sector accounted for $60.28 \%$ of the total steppe area, with an average accumulated $\mathrm{C}$ sequestration of $2186.47 \mathrm{~g} \mathrm{C} / \mathrm{m}^{2}$ and total $\mathrm{C}$ sequestration of $0.687 \mathrm{Pg} \mathrm{C}$. The $\mathrm{C}$ source sector accounted for $39.72 \%$ of the total area, with an average $\mathrm{C}$ emission of $660.32 \mathrm{~g} \mathrm{C} / \mathrm{m}^{2}$ and a total $\mathrm{C}$ emission of $0.137 \mathrm{Pg} \mathrm{C}$. This difference between $\mathrm{C}$ sequestration and $\mathrm{C}$ emission suggests that the net total $\mathrm{C}$ sink in this area is as high as $0.557 \mathrm{Pg} \mathrm{C}$ and that the annual $\mathrm{C}$ sequestration rate is $0.046 \mathrm{Pg} \mathrm{C} / \mathrm{a}$.

(2) Temporally, both the NPP and NEP of the IMGE increased from 2001 to 2012. The mean NPP ranged from $200 \mathrm{~g} \mathrm{C} / \mathrm{m}^{2}$ to $350 \mathrm{~g} \mathrm{C} / \mathrm{m}^{2}$ with an annual growth rate of $3.781 \mathrm{~g}$ $\mathrm{C} / \mathrm{m}^{2}$. The mean NEP ranged from $50 \mathrm{~g} \mathrm{C} / \mathrm{m}^{2}$ to $150 \mathrm{~g} \mathrm{C} / \mathrm{m}^{2}$ with an annual growth rate of $2.104 \mathrm{~g} \mathrm{C} / \mathrm{m}^{2}$. The variations in NPP and NEP were not completely synchronized.

(3) Spatially, our observations showed an increase in the grassland NPP in most parts of Inner Mongolia over the past 12 years, and the area of increased NPP grassland accounted for $83.6 \%$ of the total steppe area. The variations in NEP distribution were very similar to those of the NPP, but the growth rates varied. The area of increased NEP grassland accounted for $70.8 \%$ of the total steppe area.

(4) The NPP in most temperate steppes was positively correlated with precipitation, but negatively correlated with temperature. The major factor restricting the NPP in temperate steppes is moisture. Satisfactory pasture production requires optimum hydrothermal conditions. The NEP in most parts of the IMGE had a weak negative correlation with precipitation and a weak positive correlation with temperature, indicating that these climatic variables are not the major restricting factors affecting $\mathrm{C}$ sinks in the Inner Mongolia steppe.

\section{References}

Adams J M, Faure H, Faure-Denard L et al., 1990. Increases in terrestrial carbon storage from the Last Glacial Maximum to the present. Nature, 348(6303): 711-714.

Bai Yongfei, Han Xingguo, Wu Jianguo et al., 2004. Ecosystem stability and compensatory effects in the Inner Mongolia grassland. Nature, 431(7005): 181-184.

Bai Yongfei, Wu Jianguo, Xing Qi et al., 2008. Primary production and rain use efficiency across a precipitation gradient on the Mongolia plateau. Ecology, 89(8): 2140-2153.

Bao Gang, Bao Yuhai, ALateng Tuya et al., 2009. Estimation of vegetation net primary productivity using MODIS data and CASA model in Inner Mongolia. The National Agricultural Remote Sensing Technology Conference, 247-256. (in Chinese)

Battle M, Bender M L, Tans P P et al., 2000. Global carbon sinks and their variability inferred from atmospheric $\mathrm{O}_{2}$ and $\delta^{13} \mathrm{C}$. Science, 287(5462): 2467-2470.

Bond-Lamberty B, Wang C, Gower S T, 2004. A global relationship between the heterotrophic and autotrophic components of soil respiration. Global Change Biology, 10(10): 1756-1766.

Del Grosso S, Parton W, Stohlgren T et al., 2008. Global potential net primary production predicted from vegetation class, precipitation, and temperature. Ecology, 89(8): 2117-2126.

Fang Jingyun, Ke Jinhu, Tang Zhiyao et al., 2001. Implications and estimations of four terrestrial productivity parameters. Acta Phytoecologica Sinica, 25(4): 414-419. (in Chinese)

Fang Jingyun, Tang Y, Lin J et al., 2000. Global Ecology: Climate Change and Ecological Responses. Beijing: Higher Education Press. (in Chinese)

Goetz S J, Prince S D, Goward S N et al., 1999. Satellite remote sensing of primary production: An improved production efficiency modeling approach. Ecological Modelling, 122(3): 239-255.

Houghton J T, Callander B A, Varney S K, 1992. Climate Change 1992: The Supplementary Report to the IPCC Scientific Assessment. Cambridge, UK: Cambridge University Press.

Houghton J T, Ding Y, Griggs D J et al., 2001. Climate Change 2001: The Scientific Basis. Cambridge, UK: Cambridge University Press.

Liu Zhihong, McVicar T R, Li Lingtao et al., 2008. Interpolation for time series of meteorological variables using ANUSPLIN. Journal of Northwest A\&F University (Natural Science Edition), 36(10): 227-234. (in Chinese) 
Mack M C, Schuur E A G, Bret-Harte M S et al., 2004.Ecosystem carbon storage in arctic tundra reduced by long-term nutrient fertilization. Nature, 431(7007): 440-443.

Mansanet-Bataller M, Pardo Á, 2008. What you should know about carbon markets. Energies, 1(3): 120-153.

$\mathrm{Mu}$ Shaojie, Li Jianlong, Zhou Wei et al., 2013. Spatial-temporal distribution of net primary productivity and its relationship with climate factors in Inner Mongolia from 2001 to 2010. Acta Ecologica Sinica, 33(12): 3752-3764. (in Chinese)

Ni J, 2002. Carbon storage in grasslands of China. Journal of Arid Environments, 50(2): 205-218.

Niu Jianming, 2001. Impacts prediction of climatic change on distribution and production of grassland in Inner Mongolia. Acta Agrestia Sinica, 9(4): 277-282. (in Chinese)

Pan Y D, Birdsey R A, Fang J Y et al., 2011. A large and persistent carbon sink in the world's forests. Science, 333(6045): 988-993.

Peng Q, Qi Y C, Dong Y S, et al. 2014. Litter decomposition and C and N dynamics as affected by N additions in a semi-arid temperate steppe, Inner Mongolia of China. Journal of Arid Land, 6(4): 432-444.

Prince S D, Goward S N, 1995. Global primary production: A remote sensing approach. Journal of Biogeography, 22(4/5): 815-835.

Raich J W, Potter C S, Bhagawati D, 2002. Interannual variability in global soil respiration, 1980-94. Global Change Biology, 8(8): 800-812.

Raich J W, Schlesinger W H, 1992. The global carbon dioxide flux in soil respiration and its relationship to vegetation and climate. Tellus B, 44(2): 81-99.

Sarmiento J L, Gloor M, Gruber N et al., 2010. Trends and regional distributions of land and ocean carbon sinks. Biogeosciences, 7(8): 2351-2367.

Scurlock J M O, Hall D O, 1998. The global carbon sink: A grassland perspective. Global Change Biology, 4(2): 229-233.

Sitch S, Smith B, Prentice I C et al., 2003. Evaluation of ecosystem dynamics, plant geography and terrestrial carbon cycling in the LPJ dynamic global vegetation model. Global Change Biology, 9(2): 161-185.

Steffen W L, Walker B H, Ingram J S L et al., 1992. Global change and terrestrial ecosystems: The Operational Plan. Stockholm, Sweden: Global Change Report, No.21.

$\mathrm{Su}$ Yongzhong, Zhao Halin, 2002. Advances in researches on soil organic carbon storages, affecting factors and its environmental effects. Journal of Desert Research, 22(3): 220-228. (in Chinese)

Sun Honglie, 2005. Ecosystems of China. Beijing: Science Press. (in Chinese)

Tao Bo, Cao Mingkui, Li Kerang et al., 2006.Spatial pattern and its change of Chinese terrestrial net ecosystem productivity from 1981 to 2000. Science in China Series D: Earth Sciences, 36(12): 1131-1139. (in Chinese)

Woodwell G M, Whitaker R H, Reiners W A et al., 1978. The biota and the world carbon budget. Science, 199(4325): 141-146.

Yang Yuanhe, Fang Jingyun, Ma Wenhong et al., 2010. Soil carbon stock and its changes in northern China's grasslands from 1980s to 2000s. Global Change Biology, 16(11): 3036-3047.

Yang Yuanhe, Fang Jingyun, Tang Yanhong et al., 2008. Storage, patterns and controls of soil organic carbon in the Tibetan grasslands. Global Change Biology, 14(7): 1592-1599.

Yuan Lihua, Jiang Weiguo, Shen Wenming et al., 2013. The spatio-temporal changes of vegetation cover in the Yellow River Basin from 2000 to 2010. Acta Ecologica Sinica, 33(24): 7798-7806. (in Chinese)

Zhan Jinyan, Yan Haiming, Chen Bin et al., 2012. Decomposition analysis of the mechanism behind the spatial and temporal patterns of changes in carbon bio-sequestration in China. Energies, 5(2): 386-398.

Zhang G N, Chen Z H, Zhang A M et al., 2014. Influence of climate warming and nitrogen deposition on soil phosphorus composition and phosphorus availability in a temperate grassland, China. Journal of Arid Land, 6(2): 156-163.

Zhang Li, Guo Huadong, Jia Gensuo et al., 2014. Net ecosystem productivity of temperate grasslands in northern China: An upscaling study. Agricultural and Forest Meteorology, 184: 71-81.

Zhang Qingyu, Zhao Dongsheng, Wu Shaohong et al., 2013. Research on vegetation changes and influence factors based on eco-geographical regions of Inner Mongolia. Scientia Geographica Sinica, 33(5): 594-601. (in Chinese)

Zhao Tongqian, Ouyang Zhiyun, Jia Liangqing et al., 2004. Ecosystem services and their valuation of China grassland. Acta Ecologica Sinica, 24(6): 1101-1110. (in Chinese)

Zhu Wenquan, Chen Yunhao, Xu Dan et al., 2005. Advances in terrestrial net primary productivity (NPP) estimation models. Chinese Journal of Ecology, 24(3): 296-300. (in Chinese)

Zhu Wenquan, Pan Yaozhong, Zhang Jinshui, 2007. Estimation of net primary productivity of Chinese terrestrial vegetation based on remote sensing. Journal of Plant Ecology, 31(3): 413-424. (in Chinese) 